\title{
CHANGES IN PULMONARY VOLUME FOLLOWING LOBECTOMY FOR BRONCHIECTASIS ${ }^{1}$
}

\author{
By GUSTAF E. LINDSKOG \\ (From the Department of Surgery, Yale University, The School of Medicine, New Haven)
}

(Received for publication December 12, 1938)

The ablation of any considerable portion of a vitally functioning organ immediately raises the question of a reduction in functional capacity. With respect to the removal of one or more lobes of the lung, one may ask; first, what are the immediate and remote effects on the total lung volume and its component parts; second, what changes occur in the hemorespiratory exchange, and how long do they persist?

Lilienthal (1) anticipated the first question in 1926 when he published reports on the vital capacity in 11 patients who had been subjected to partial lobectomy. Although he had no preoperative control observations, he found, following operation, that the vital capacity ranged from 30 to 100 per cent of the theoretical minimal normal for the individual, and indicated that children showed a more facile return toward normal values.

Heuer and Andrus (2) were the first to report a study of hemorespiratory adjustments following experimental pneumonectomy. Dogs studied under resting conditions after removal of one entire lung showed an increase in alveolar $\mathrm{CO}_{2}$ lasting an average of 30 days, a slight increase in blood $\mathrm{CO}_{2}$ lasting 25 days, a fall in alveolar oxygen tension for 28 to 66 days, and decrease in blood oxygen content up to the 11th day, returning to normal by the 30th day.

Longacre, Carter, and Quill (3) have more recently modified and expanded these observations to include a study of the response to exercise in dogs before and after excision of the left lung. They have demonstrated that disturbances may persist for as long as five months (at least) after operation, as reflected in elevation of temperature and pulse rate, partial oxygen unsaturation of the arterial blood, and diminished tolerance to anoxemia; these effects were present even though the measured subtidal lung volume in some animals had returned to the preoperative level dur-

1 Aided by a grant from the Fluid Research Funds of the Yale University School of Medicine. ing this time. Derangements of this same type may occur with removal of one or two lobes, but should be significantly less severe both as to degree or duration than when an entire lung is removed.

Our treatment of a group of patients with bronchiectasis and chronic lung abscess by lobectomy has afforded us the opportunity to study changes in the components of the lung volume picture by the determination of preoperative levels and then repetition of observations over long periods of time after operation. Five of our fourteen operative cases have seemed suitable for this study. The others were not utilized because of various undesirable preoperative situations, such as previous deforming operations on the chest wall, open bronchial fistulae, overwhelming cough and expectoration, and too recent recovery from hemorrhage and pneumonia.

\section{DEFINITIONS}

Subtidal volume (functional residual): The air content of the respiratory tract at the conclusion of a normal (tidal) expiration.

$V$ ital capacity: The volume of air expired from the maximal inspiratory level to the maximal expiratory level.

Complementary air: The volume of air inspired from the level of normal inspiration to the maximal inspiratory level.

Supplementary or reserve air: The volume of air expired from the resting expiratory level to the maximal expiratory level.

Mean tidal air: The average volume of air inspired or expired between the normal inspiratory and expiratory levels.

Total volume: The air content of the respiratory tract at the maximal inspiratory level (that is, the sum of the complementary, mean tidal, and subtidal air).

\section{METHODS}

Patients were studied either in the fasting state or several hours after the last meal in the supine horizontal 
position, the head resting on one pillow. All restraining clothing was removed and the arms laid parallel to the sides. The components of the vital capacity curve were determined in the well known manner with a Roth-Benedict recording spirometer. The subtidal volume was determined by the technic of Christie (4). This method depends on the dilution of alveolar nitrogen in the subject's lung by a controlled volume of oxygen rebreathed for five to seven minutes in a gas-tight spirometer system of calibrated dead space. A determination of the nitrogen percentage in the mixed spirometer gas sample at the end of a breathing period permits the calculation of the subtidal volume. The patients were studied preoperatively, and postoperatively after any existing bronchial fistulae had closed. The wound was usually healed and the pulmonary fields were clear by roentgenograms.

\section{PROTOCOLS}

A summary of the five cases is presented.

Case 1. Patient, W. D., age 26, white male, ItalianAmerican laborer (Table I).

TABLE I

Case 1 (Patient W. D.). Bronchiectasis. Right lower lobectomy (one stage) *

\begin{tabular}{l|c|c|c|c|c|c}
\hline \hline & $\begin{array}{c}\text { Sub- } \\
\text { tidal } \\
\text { vol- } \\
\text { ume }\end{array}$ & $\begin{array}{c}\text { Vital } \\
\text { capac- } \\
\text { ity }\end{array}$ & $\begin{array}{c}\text { Re- } \\
\text { serve } \\
\text { air }\end{array}$ & $\begin{array}{c}\text { Mean } \\
\text { tidal } \\
\text { air }\end{array}$ & $\begin{array}{c}\text { Com- } \\
\text { ple- } \\
\text { men- } \\
\text { tary } \\
\text { air }\end{array}$ & $\begin{array}{c}\text { Total } \\
\text { vol- } \\
\text { ume }\end{array}$ \\
\hline September 24, 1936... & 1650 & 1910 & 260 & 530 & 1120 & 3300 \\
\hline December 5, 1936.... & 1910 & 1810 & 430 & 540 & 840 & 3290 \\
$\begin{array}{l}\text { September 24, 1937... } \\
\text { December 22, 1937... }\end{array}$ & 1640 & 2230 & 410 & 510 & 1310 & 3480 \\
\hline
\end{tabular}

* Date of lobectomy-October 8, 1936.

Illness began in January, 1934, with cough, expectoration, chills and fever, subsiding in a few weeks so that he was able to return to work. Cough recurred, however, and in May, 1934, a roentgenogram showed an infiltration of the right lower lobe at its apex. Shortly, he was admitted to a sanatorium where he expectorated 250 to 275 cc. of purulent sputum daily, negative for acid-fast organisms on direct smear but occasionally positive on concentration. Bronchoscopic examination revealed an ulcerating, granulating lesion of the right lower lobe bronchus which was biopsied and a report of chronic non-tuberculous infection made. A right pneumothorax was begun in June, 1934. Despite the continued pneumothorax and a right temporary phrenic nerve paralysis performed in December, 1934, he continued to have daily fever, the expectoration of large quantities of foul-smelling sputum, chest pain, and hemoptyses until his admission to the New Haven Hospital on September 14, 1936. At that time six sputum examinations and one guinea pig inoculation were negative for acid-fast organisms. Another bronchoscopic examination revealed no specific pathology in the right lower lobe from which pus was constantly exuding. An injection of lipiodol into this lobe showed a saccular dilatation of the medial bronchi in the posterior portion of the lobe and a collection of the lipiodol in two definite cavities. On October 8, 1936 under intratracheal cyclopropane anesthesia a densely adherent lower lobe was removed. The remaining cavity was drained by an intercostal catheter in the 9th space. He was discharged on the 61st postoperative day afebrile and free of sputum. At present, he appears to be in excellent condition, weighs between 180 to $190 \mathrm{lbs}$., has an excellent appetite, no cough or sputum except with an occasional head cold. Chest wound is well healed, and he has been working. Pathological diagnosis : bronchiectasis, no evidence of tuberculosis.

Case 2. Patient, G. H., age 16, white, male, American schoolboy (Table II).

TABLE II

Case 2 (Patient G. H.). Bronchiectasis. Left lower lobectomy (two stages) *

\begin{tabular}{l|c|c|c|c|c|c}
\hline \hline & $\begin{array}{c}\text { Sub- } \\
\text { tidal } \\
\text { volume }\end{array}$ & $\begin{array}{c}\text { Vital } \\
\text { capac- } \\
\text { ity }\end{array}$ & $\begin{array}{c}\text { Re- } \\
\text { serve } \\
\text { air }\end{array}$ & $\begin{array}{c}\text { Mean } \\
\text { tidal } \\
\text { air }\end{array}$ & $\begin{array}{c}\text { Com- } \\
\text { ple- } \\
\text { men- } \\
\text { tary } \\
\text { air }\end{array}$ & $\begin{array}{c}\text { Total } \\
\text { vol- } \\
\text { ume }\end{array}$ \\
\hline April 23, 1937 ...... & $\begin{array}{r}2410 \\
\pm 10\end{array}$ & 1930 & 300 & 560 & 1070 & 4040 \\
\hline September 10, 1937.. & $\begin{array}{r}2900 \\
\pm 80\end{array}$ & 2880 & 540 & 560 & 1780 & 5240 \\
December 15, 1937.. & $\begin{array}{r}3210 \\
\pm 120\end{array}$ & 3190 & 570 & 600 & 2020 & 5830 \\
October 18, 1938.... & $\begin{aligned} 3910 \\
\pm 110\end{aligned}$ & 3550 & 720 & 660 & 2170 & 6740 \\
\hline
\end{tabular}

* Date of first stage May 11, 1937. Date of lobectomy (left lower) June 15, 1937.

In August, 1936, while vacationing at the seashore he caught a cold and for about a week had a non-productive cough with pain in the mid-chest region. Following chills and fever, he was admitted to a hospital where a diagnosis of pneumonia was made. He began to have night sweats and gradually increasing amounts of sputum which became quite thick and evil-smelling. After four weeks in the hospital he went home but his sputum continued to increase and became more foul. Postural drainage and supportive measures did not improve his condition, and he lost 20 pounds in weight. Two paternal uncles died of pulmonary tuberculosis, but there was no contact with the patient.

He was admitted to the New Haven Hospital on November 19,1936, acutely ill. Sputum output ran as high as 230 grams daily. His temperature and white count were elevated. A roentgen examination of the chest revealed atelectasis and pneumonia in the left lower lobe. The tuberculin test was negative to $0.1 \mathrm{mgm}$, and the sputum was negative for acid-fast organisms. A lipiodol examination revealed a saccular bronchiectasis of the left lower lobe and a normal right bronchial tree. After bronchoscopic treatment the patient began to improve. A left artificial pneumothorax was carried on for three months preparatory to an operative exploration, and the 
patient was discharged home to convalesce. He returned in April, 1937, after a fairly good winter, with low-grade fever, increasing sputum, and loss of six pounds in weight. On May 11, 1937, a first-stage lobectomy was done. The sputum output showed a remarkable immediate and permanent improvement. On June 15, five weeks after the first operation, the wound was re-opened, and the lower lobe was easily excised. The convalescence was uncomplicated. The chest wound healed per primam. The drainage tube was removed from the chest on the 27th day. There was never clinical evidence of a bronchial fistula. A roentgenogram of the chest on July 14 showed a clearing of the left lung field with compensatory enlargement of the left upper lobe. The patient was discharged on the 32d postoperative day.

Sections of the excised lobe revealed many dilated, saccular, thin-walled bronchiectatic channels with but little involvement of the surrounding lung parenchyma.

The patient is now entirely symptom-free and has returned to his high school classes, taking part in all activities including gymnastics.

Case 3. Patient, E. M., age 22, white, female, American (Table III).

TABLE III

Case 3 (Patient E. M.). Bronchiectasis. Left lower lobectomy (two stage) *

\begin{tabular}{|c|c|c|c|c|c|c|}
\hline & $\begin{array}{l}\text { Sub- } \\
\text { tidal } \\
\text { vol- } \\
\text { ume }\end{array}$ & $\begin{array}{c}\text { Vital } \\
\text { capac- } \\
\text { ity }\end{array}$ & $\begin{array}{c}\text { Re- } \\
\text { serve } \\
\text { air }\end{array}$ & $\begin{array}{c}\text { Mean } \\
\text { tidal } \\
\text { air }\end{array}$ & $\begin{array}{c}\text { Com- } \\
\text { ple- } \\
\text { men- } \\
\text { tary } \\
\text { air }\end{array}$ & $\begin{array}{l}\text { Total } \\
\text { vol- } \\
\text { ume }\end{array}$ \\
\hline May $12,1937 \ldots \ldots \ldots$ & 2970 & 2560 & 590 & 540 & 1430 & 4940 \\
\hline $\begin{array}{l}\text { September } 17,1937 \ldots \\
\text { December } 8,1937 \ldots \ldots \\
\text { April } 19,1938 \ldots \ldots \\
\text { October } 12,1938 \ldots \ldots\end{array}$ & $\begin{array}{l}3010 \\
2880 \\
3250 \\
3550\end{array}$ & $\begin{array}{l}2480 \\
2660 \\
2830 \\
2800\end{array}$ & $\begin{array}{l}780 \\
720 \\
740 \\
700\end{array}$ & $\begin{array}{l}540 \\
560 \\
600 \\
570\end{array}$ & $\begin{array}{l}1160 \\
1380 \\
1490 \\
1530\end{array}$ & $\begin{array}{l}4710 \\
4820 \\
5340 \\
5650\end{array}$ \\
\hline
\end{tabular}

* Date of first stage May 14, 1937. Date of lobectomy July 2, 1937.

At the age of two the patient had infantile paralysis which left her with both legs flaccid. At ten she began to have nasal discharge, chronic cough, and sputum. At 12 she had whooping cough, following which her cough was always much worse and about three times a day she raised a half cupful of thick, purulent malodorous sputum. The patient's father was said to have a chronic pulmonary lesion diagnosed as tuberculosis.

She was admitted to the New Haven Hospital on March 29, 1937. She presented slight dullness and suppression of breath sounds at the left base posteriorly with fine moist râles. There was no clubbing or cyanosis of the finger tips. A lipiodol examination of the right and left lower lobes was carried out, and showed a bronchiectatic dilatation of the left lower lobe bronchi. Sputum was repeatedly negative for acid-fast organisms. A series of eight bronchoscopic drainages was carried out without any improvement in the cough or amount of sputum which approximated 30 to 50 grams daily. On May 14, 1937, under avertin and intratracheal cyclopro- pane anesthesia a first stage operation was performed, the pleural surfaces being free of adhesions. The patient made a smooth convalescence and returned home to rest between stages. She returned on June 29, 1937 following a very severe hemoptysis, approximating one cupful of fresh blood. On July 2, the left chest was re-opened through the healed wound with an additional resection of the 7th rib and the left lower lobe was removed. The chest was drained by means of an intercostal tube. The patient made an excellent convalescence. Evidence of a small bronchopleural fistula was present from about the 15 th to the 21st day. Sputum was absent entirely after the 24th day, and the patient was discharged home in six weeks.

She has gained in weight, has had no further sputum or blood-streaking, and cough is only occasionally present when associated with a maxillary sinusitis, for which she has since submitted to a submucous resection without any chest complications.

Case 4. Patient, G. R., age 16, white, Italian-American male (Table IV).

TABLE IV

Case 4 (Patient G. R.). Bilateral bronchiectasis. Bilobectomy (right middle and lower lobes) *

\begin{tabular}{|c|c|c|c|c|c|c|}
\hline & $\begin{array}{l}\text { Sub- } \\
\text { tidal } \\
\text { vol- } \\
\text { ume }\end{array}$ & $\begin{array}{c}\text { Vital } \\
\text { capac- } \\
\text { ity }\end{array}$ & $\begin{array}{l}\text { Re- } \\
\text { serve } \\
\text { air }\end{array}$ & $\begin{array}{l}\text { Mean } \\
\text { tidal } \\
\text { air }\end{array}$ & $\begin{array}{l}\text { Com- } \\
\text { ple- } \\
\text { men- } \\
\text { tary } \\
\text { air }\end{array}$ & $\begin{array}{l}\text { Total } \\
\text { vol- } \\
\text { ume }\end{array}$ \\
\hline September $11,1937 \ldots$ & $\begin{array}{r}2100 \\
\pm 10\end{array}$ & 1160 & 210 & 460 & 490 & 3050 \\
\hline January $5,1938 .$. & 2090 & 1360 & 380 & 460 & 520 & 3070 \\
\hline May 23, 1938. & 1930 & 1730 & 450 & 480 & 800 & 3210 \\
\hline October $11,1938$. & $\begin{array}{l}2360 \\
\pm 90\end{array}$ & 1910 & 490 & 520 & 900 & 3780 \\
\hline
\end{tabular}

* Date of operation-September 14, 1937.

At the age of two years the patient had diphtheria followed by bilateral bronchopneumonia. He developed a right empyema which was treated by thoracotomy at another hospital. Following this illness the patient had a continual chronic cough with the production of scant, purulent sputum and was always under par physically. At the age of seven, roentgenograms of the chest were made and were reported to show fibrotic changes in both lower lung fields. At the age of twelve because of persistent cough and sputum, general malaise, weakness, and inferior general development the patient had lipiodol examination of the chest with a resultant diagnosis of bilateral bronchiectasis involving the lower lobes. At the age of thirteen he had a very severe hemoptysis, and the tuberculin test which had previously been negative became positive. On July 13, 1937, at the age of sixteen he was admitted to this hospital with a complaint of fever and pain in the left chest. Physical and roentgenographic examination revealed a pneumonia involving both lower lobes with fluid in the left chest. On the 3d 
day of his hospital illness pus was withdrawn from the left chest by thoracentesis. A rib-resection thoracotomy for drainage was carried out. Following this the patient's general condition improved slowly, and the empyema cavity became obliterated. On September 2 a lipiodol injection of the right middle and lower lobes showed extensive bronchiectatic changes. Because of the long standing history of bilateral lower lobe pathology with the many complications, it was decided to carry out a resection of the right middle and lower lobes. This was performed on September 14, 1937. The immediate postoperative convalescence was quite stormy, being complicated by the development of obstruction in the right upper lobe bronchus presumably due to mucus with inflammatory swelling, and a pneumonia flaring up again in the left lower lobe. Despite these serious complications, however, the patient was well on the road to convalescence in about ten days, since when he has continued to gain in weight, strength, and to improve in general condition. A bronchial fistula appeared early during his convalescence but closed without further treatment. Patient goes to school, is able to play nine innings of baseball; slight cough and sputum are still present, presumably from the diseased left lower lobe.

Case 5. Patient, I. E., age 17, white, female, Portuguese.

TABLE V

Case 5 (Patient I. E.). Bronchiectasis. Right middle and lower lobectomy (two stages) *

\begin{tabular}{l|c|c|c|c|c|c|c}
\hline \hline & $\begin{array}{c}\text { Sub- } \\
\text { tidal } \\
\text { vol- } \\
\text { ume }\end{array}$ & $\begin{array}{c}\text { Vital } \\
\text { capac- } \\
\text { ity }\end{array}$ & $\begin{array}{c}\text { Re- } \\
\text { serve } \\
\text { air }\end{array}$ & $\begin{array}{c}\text { Mean } \\
\text { tidal } \\
\text { air }\end{array}$ & $\begin{array}{c}\text { Com- } \\
\text { ple- } \\
\text { men- } \\
\text { tary } \\
\text { air }\end{array}$ & $\begin{array}{c}\text { Total } \\
\text { vol- } \\
\text { ume }\end{array}$ \\
\hline May 31, 1938........ & $\begin{array}{c}1860 \\
\pm 90\end{array}$ & 1620 & 270 & 480 & 870 & 3210 \\
\hline October 5, 1938...... & $\begin{array}{c}1780 \\
\pm 60\end{array}$ & 1670 & 300 & 480 & 890 & 3150 \\
\hline
\end{tabular}

Date of first stage March 29, 1938.

* Date of lobectomy-June 2, 1938.

She was first admitted to the New Haven Hospital on January 18, 1937, with a complaint of cough. Eight months before admission, the patient had a respiratory infection which was characterized by an irritative cough productive of yellowish sputum, occasionally pink-tinged, to the extent of about 10 grams daily. There was some associated presternal pain and tendency to sweat. A racking cough kept the patient awake at night. After about one month in bed she felt better, but during the following summer was troubled by occasional bouts of mild fever lasting a few days. The patient has also noted progressive asthenia and a tendency to vertigo on exercising. The family history revealed that maternal grandmother and grandfather both died of tuberculosis.

At the right pulmonary base posteriorly there was an area of dullness to flatness with suppressed bronchial breathing, and coarse râles were heard at the upper margin of this area. Seventeen sputum examinations were negative for acid-fast bacilli. A roentgen examination of the chest showed atelectasis of the right lower lobe with elevation of the right leaf of the diaphragm. A lipiodol injection revealed bronchiectatic dilatations in the atelectatic right lower lobe. In February, 1937, after bronchoscopic treatment, the patient was discharged improved to her home. In July she had an increase in cough and sputum with several frank but small hemoptyses. In the early winter she began to notice severe pleuritic type of pain in the right chest. The sputum continued to increase in amount, became rather foul, and she had hemoptyses. She was readmitted to the hospital in March, 1938, for pulmonary lobectomy. A repeat lipiodol examination of the right lower lobe was carried out and showed the same evidences of bronchiectasis. The right middle lobe injection showed no definite evidence of bronchiectasis, and the left lower lobe appeared normal. At operation the right lower lobe and right middle lobes were both found to be completely atelectatic and quite dense in texture. There were practically no adhesions on the upper lobe. Consequently the parietal pleura was abraded with dry gauze and the chest closed without removal of the lobes. The patient made a smooth convalescence and was discharged to her home on the 17th postoperative day.

The patient was readmitted in May, 1938, having continued to raise sputum of the same quantity and quality as prior to the first stage with slight blood-streaking at one time. A second stage right middle and lower lobectomy was carried out and the chest cavity drained. The immediate convalescence was quite satisfactory, but the late convalescence was complicated and prolonged by the development of two small empyema pockets, one in the anterior mediastinal surface of the right pleural cavity and the other one posteriorly at the right base. These required separate incision and drainage, following which the patient made an excellent recovery. At the present time she is free of sputum, entirely afebrile, and gaining weight.

\section{DISCUSSION}

Individuals such as these patients whose lung is the site of an acute or chronic inflammatory lesion usually demonstrate a reduction of the pulmonary volume in one or more of its component parts. This reduction may be due to, (1), the space-occupying characteristics of the pathological lesion; (2), obstruction in the respiratory passages, due to bronchitic swelling or exudate; (3), increased elastic tension of the diseased parenchyma (5); (4), possibly reflex disturbances in the nervous control of the respiratory level.

The observations of the late Hans Jacobeus (6) are of interest in this connection. By means of a specially designed bronchoscope, he was able to cannulate the primary bronchi and to determine separately by spirometric technic the respiratory 
exchange in each lung. While the experiments are possibly open to some criticism because of technical difficulties, they seem to show that a diseased lung may have a respiratory function (as measured by minute ventilation and oxygen absorption) drastically reduced, more severely than roentgenographic or physical examination would sometimes lead one to suspect.

When a chronic inflammatory lesion in the lung has been successfully excised, (1), a space occupying lesion of depressed respiratory activity is thereby removed; $(2)$, infectious exudate in the tracheo-bronchial tree is abolished; (3), secondary inflammatory changes in the remaining lung parenchyma therefore tend to resolve; (4), compensatory hypertrophy occurs in the remaining lobes.

These considerations explain the results observed in the five cases here presented.

\section{CONCLUSION}

Clinically successful resection of one or two bronchiectatic lung lobes causes no permanent reduction in pulmonary volume and its component parts, and may actually be followed by a progressive increase and return toward normal values. The question as to whether the hemorespiratory exchange shows a comparable satisfactory adjustment has not been investigated in these cases.

\section{BIBLIOGRAPHY}

1. Lilienthal, H., Vital capacity following lobectomy. Arch. Surg., 1926, 12, 286.

2. Heuer, G. J., and Andrus, W. D. W., The alveolar and blood gas changes following pneumectomy. Bull. Johns Hopkins Hosp., 1922, 33, 130.

3. Longacre, J. J., Carter, B. N., and Quill, L. McG., An experimental study of some of the physiologic changes following total pneumonectomy. J. Thoracic Surg., 1937, 6, 237.

4. Christie, R. V., The lung volume and its subdivisions. I. Methods of measurement. J. Clin. Invest., 1932, $11,1099$.

5. Van Allen, C. M., and Wu, C., Increased elastic tension of the lung in experimental pneumonia. $\mathrm{J}$. Clin. Invest., 1932, 11, 589.

6. Jacobeus, H. C., Bronchospirometry. A review of present experiences and some further investigations. J. Thoracic Surg., 1938, 7, 235. 